\title{
Practicing perfection: How concert soloists prepare for performance
}

\author{
Roger Chaffin and Topher Logan
}

University of Connecticut

Received 03.04.2006

Accepted 15.16.2006

\section{Keywords}

music performance, expert memory, skill learning

\begin{abstract}
Musical performances by concert soloists in the Western classical tradition are normally memorized. For memory to work reliably under the pressures of the concert stage, the performance must be practiced until it is thoroughly automatic. At the same time, the performance must be fresh and spontaneous in order to communicate emotionally with the audience. The resolution of this apparent contradiction is provided by longitudinal case studies of concert soloists preparing new works for performance. Like expert memorists in other domains, experienced musicians use highly practiced retrieval schemes to accomplish their extraordinary feats of memory. Performers have a mental map of the piece in mind as they perform that tells them where they are and what comes next - a series of landmarks, hierarchically organized by the sections and subsections of the music. The
\end{abstract}

musician attends to these performance cues in order to ensure that the performance unfolds as planned. Performance cues are established by thinking about a particular feature of the music during practice so that it later comes to mind automatically. Performance cues help the soloist consciously monitor and control the rapid, automatic actions of playing, while adjusting to the needs of the moment. During practice, the musician attends mostly to basic performance cues representing critical technical features (e.g., fingerings), and interpretive performance cues, representing phrasings, and changes in dynamics, tempo, and timbre. During performance, the musician hopes to attend mainly to expressive performance cues representing the musical feelings to be conveyed to the audience (e.g. excitement). We illustrate this analysis with a typical case study of a concert pianist learning J.S. Bach's Italian Concerto (Presto).

\section{INTRODUCTION}

We have all experienced the fascination and awe of witnessing a world class performance, whether a musician in a virtuoso rendition, an ice skater making triple axel leaps, or a kayaker hurtling down a class six rapid. And most of us have marveled at the skill that makes such feats possible. For example, the performance of even a moderately complex piano piece places incredible demands on memory and physical dexterity, requiring the execution of between 10 and 20 notes a

second for minutes on end. How does a performer do this: remembering it all, hitting every note, and at the same time creating beautiful music? On the one hand, extended practice is needed if memory is to operate reliably (Ericsson \& Kintsch, 1995), particularly under the pressure of the concert stage. On the other hand, audiences value the feeling of freshness and spontane-

Correspondence concerning this article should be addressed to Roger Chaffin, Department of Psychology U-1020 University of Connecticut Storrs CT 06269-1020 USA email: Roger. Chaffin@Uconn.edu tel: 860-529-5428 
ity (Repp, 1998; Sundberg, Friberg, \& Fryden, 1991). How does a performer resolve these apparently contradictory demands?

The answer comes from longitudinal case studies of concert soloists preparing for performance. Music practice naturally produces a detailed behavioral record that is not available for the learning of most types of highly skilled behavior. During practice, musicians constantly start, stop, back up, and repeat, making split-second decisions as they review every aspect of technique, interpretation, and performance. The behavioral record generated in practice provides a window into the cognitive processes involved in developing a high level skill. By itself, however, the behavioral record is relatively uninformative unless supplemented by an understanding of the musician's goals (Chaffin \& Imreh, 2001).

Experienced musicians have a detailed understanding of the factors that go into their decisions during practice (Hallam, 1995a, 1995b) and in the studies reviewed here, this understanding provides an important source of information. The musicians were asked to provide detailed, retrospective reports about all of the features of the music they thought about during practice. They marked on copies of the score every point where they had thought about each aspect of the music: structure, basic technique, interpretation, and performance. When these reports were correlated with measures of practice, recall, and performance, those aspects of the music affecting each activity could be identified. For example, if playing started or stopped at places where the musician reported needing to recall information from memory, this suggested that the musician was practicing memory retrieval. In this way, the detailed behavioral record naturally provided by music practice can be interpreted.

Case studies are the method of choice for studying highly developed skills like those of a concert soloist. The $20+$ years of training required for a career on the concert stage increases the normal range of individual differences so that aggregating observations across individuals risks obscuring the phenomena of interest (Ericsson \& Oliver, 1988). Here we describe conclusions about expert musical performance based primarily on case studies of a concert pianist (Chaffin \& Imreh, 2001, 2002, Chaffin, Imreh \& Crawford, 2002; Chaffin, Lemieux \& Chen, 2004, 2006; Chaffin, Imreh, Lemieux \& Chen, 2003), a jazz pianist (Noice, Chaffin, Jeffrey \& Noice, in press), a cello soloist (Lisboa, Chaffin, Schiaroli \& Barrera, 2004), and a soprano and conductor (Ginsborg, Chaffin \& Nicholson, 2006). We use these data to test the application to music of theories developed to account for skilled memory in other domains, such as chess and acting, (Ericsson \& Kintsch,
1995), intuitive problem solving (Gobet \& Simon, 1996), and motor skill (Van Orden, Holden, \& Turvey, 2003).

Experts in any domain memorize with a facility that seems superhuman (Chase \& Simon, 1973, Gobet \& Simon, 1996). Musicians are no exception; their biographies are full of tales of amazing memory feats, such as the story of the young Mozart's ability to write from memory Allegri's Miserere after two hearings (Cooke, 1999) or Jorge Bolet's memorization of Liszt's Mephisto Waltz in an hour and a quarter (Noyle, 1987). The abilities of other expert memorists have been attributed to the use of highly practiced retrieval strategies (Ericsson \& Kintsch, 1995). In describing memory for skilled activity, Ericsson \& Kintsch argue that the end products of processing can be stored in long term memory and accessed through retrieval cues in short term memory. It is not, however, obvious that principles of expert memory derived from the study of memory for chess boards (Chase \& Ericsson, 1982; Chase \& Simon, 1973), digit strings (Chase \& Ericsson, 1982; Thompson, Cowan \& Friedman, 1993), and dinner orders (Ericsson \& Oliver, 1989) apply to musical performance. Motor and auditory memory play crucial roles in musical memory but not in these other domains. In spite of the large differences, the case studies of concert soloists reviewed here suggest that the same principles apply.

The feats of expert memorists have been explained in terms of three principles: meaningful encoding of novel material, use of a well learned retrieval structure, and extended practice to decrease the time needed for retrieval from long-term memory (Ericsson \& Kintsch, 1995). The same three principles appear to apply to expert music performance (Chaffin, Imreh \& Crawford, 2002; Krampe \& Ericsson, 1996). First, experts' knowledge of their domain of expertise allows them to encode new information in terms of ready-made chunks already stored in memory (Miller, 1956; Tulving, 1962; Mandler \& Pearlstone, 1966). For a musician, these include familiar patterns like chords, scales, and arpeggios, whose practice forms an important part of every musician's training (Halpern \& Bower, 1982). Second, expert memory in any domain requires a retrieval scheme to organize the cues that provide access to the chunks of information in long-term memory (Ericsson \& Oliver, 1989). For a musician, the formal structure of the music conveniently provides a ready-made hierarchical organization to serve as a retrieval scheme (Chaffin \& Imreh, 1997, 2002; Williamon \& Valentine, 2002). For example, Figure 1 shows the structure of one of the pieces whose preparation was the subject of a case study, the Italian Concerto (Presto) 
by J.S. Bach. The piece is hierarchically organized into movements, sections, sub-sections, and bars within which more specific retrieval cues (performance cues) are embedded. The third principle of expert memory is that prolonged practice is required to bring the speed of operation of this retrieval scheme up to the point where an expert can rely on long-term memory to perform tasks for which most people would use working memory (Ericsson \& Kintsch, 1995). For the musician, this involves practicing memory retrieval until it is rapid and reliable enough to keep pace with the tempo required for performance.

Rapid memory retrieval is important in music performance to prevent the hands from "running away" as motor performance outstrips the corresponding conceptual representation in working memory. Practice is needed to coordinate motor performance with retrieval from declarative long-term memory so that the memory for what comes next arrives in working memory at just the right moment, before the corresponding motor sequences, but not so far in advance as to interfere with the execution of the preceding notes. ${ }^{1} \mathrm{~A}$ goal of the preparation for public performance is to devise a plan that ensures that memory does not fail while under the pressure of a live performance. In an attempt to explain the mechanisms by which performers plan production sequences, Palmer and Pfordresher (2003) developed an incremental planning model, which treats memory for serial order in music performance as response preparation rather than response selection. In their framework, serial ordering in music is determined by contextual associations among pitch events, such as those prescribed by rhythm and meter. They argue that response preparation for a sequence of events is in part a function of metrical similarity (the similarity of metrical accent strength between events) and serial proximity between events. By fitting the predictions of the model to behavioral data, they determined that errors increased with metrical similarity and serial proximity and that the range of planning increased with experience and decreased with tempo. This finding could potentially help explain why even experienced performers often find it difficult to keep head and hands together in a fast piece where there are no pauses or long notes which would allow time to think ahead. As the pianist in a study of the Italian Concerto described below explained:

"My fingers were playing the notes just fine. The practice I needed was in my head. I had to learn to keep track of where I was. It was a matter of learning exactly what I needed to be thinking of as I played, and at exactly what point so that as I approached a

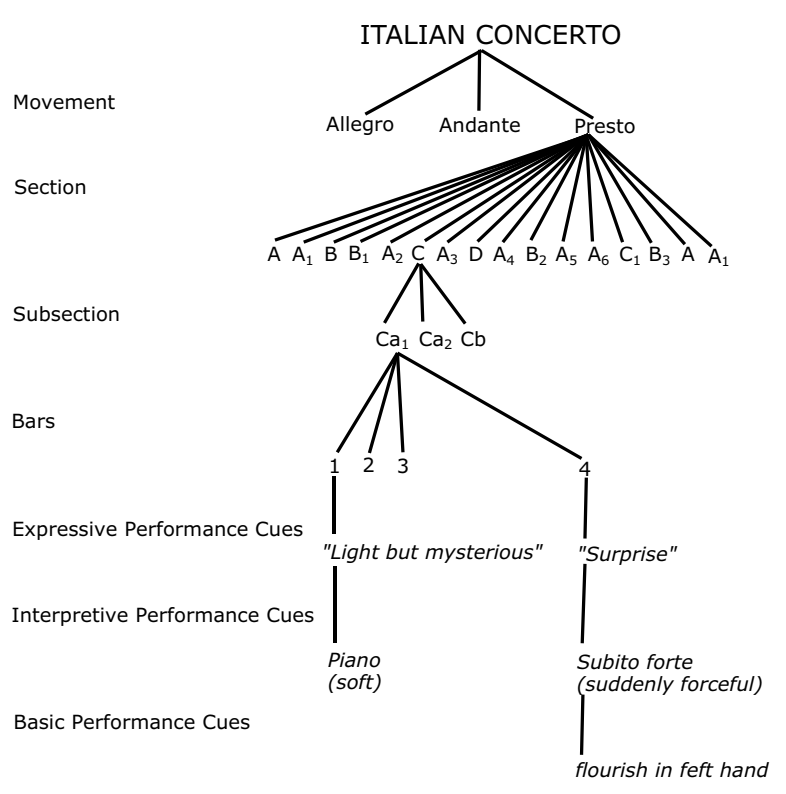

\section{Figure 1.}

Hypothetical hierarchical retrieval scheme "unpacked" for Section $C$ of the Presto. Main themes (sections) are represented by capital letters. Section C is "unpacked" into subsections (Ca1, Ca2, Cb). Subsection Ca1 is further "unpacked" into its performance cues (adapted with permission, from Chaffin et al., 2002, p. 200)

switching point I would automatically think about where I was, and the switch would go" (Chaffin et al., 2002, p. 224).

We call the kind of memory retrieval cues that the musician is talking about here, performance cues. Performance cues are the landmarks of the piece that an experienced musician attends to during performance, carefully selected and rehearsed during practice so that they come to mind automatically and effortlessly as the piece unfolds, eliciting the highly practiced movements of fingers, hands, and arms. Performance cues become an integral part of the performance and provide a means of consciously monitoring and controlling the rapid, automatic actions of the hands.

Performers are faced with a paradox. On the one hand, the performance must be completely automatic to cope with the highly charged atmosphere of the concert stage. Every action must be automatic or it will be forgotten in the adrenaline rush of stepping out in front of an audience. On the other hand, performance is a creative activity, not simply the rote repetition of overlearned movements. Most performers would agree with the eminent Russian pianist Emil Gilels that:

"When I am in top form... the ideas are always different. Sometimes I play with greater changes in dynamics, sometimes with less... I must say it is different each time I play, and it is a process which... includes mastery of the work, knowing the details, be- 
ing comfortable with it, and then adding the fantasy (Mach, 1991, vol. 2, p. 123).

Gilels apparently considered his ability to vary his performances to be a reflection of his artistry and skill. Gilels is not talking here about the sort of random variability that is present in any psychological process (Gilden, 2001), but about differences in the musical gestures of his interpretation. These are the carefully calibrated nuances of timing, dynamics, and timbre that are responsible for the ritardandos, crescendos, and phrasings that bring a piece of music to life (Shaffer, 1984; Shaffer, Clarke \& Todd, 1985; see Gabrielsson, 1999, for a review). Each performer's interpretation is unique, and soloists' reputations depend on their ability to develop interpretations that are both distinctive and convincing. Flexibility is a general characteristic of skilled musical performance as it is of other motor skills (Latash, Scholz \& Schoner, 2002; Todorov \& Jordan, 2002; Van Orden et al., 2003). For the musician, flexibility is necessary to adapt to the idiosyncrasies of each instrument, hall, and audience, to provide a feeling of freshness and spontaneity, and to recover from the mistakes that are an inevitable aspect of any live performance.

Performance cues provide flexibility by allowing the performer to remain mindful of a memorized performance that has become automatic through extended practice. Performance cues allow the musician to attend to some aspects of the performance while allowing others to be executed automatically (Chaffin et al., 2006). Performance cues are the retrieval cues that elicit the knowledge of what comes next from long term memory, providing the musician with a mental map of the piece in working memory that continuously unfolds as the performance progresses. Careful preparation of these cues makes it possible for soloists to reliably perform challenging works from memory on the concert stage.

We can distinguish four types of performance cue. Structural cues are critical places in the formal structure of the music, such as section boundaries, where musical material changes. Expressive cues represent musical feelings to be conveyed to the audience, e.g., surprise or excitement. Interpretive cues are places where some aspect of interpretation requires attention, e.g., a change of tempo or dynamics. Basic cues represent the critical details of technique or musical structure that must be executed exactly for the performance to unfold as intended, e.g., the use of a particular fingering in order to set up the hand up for what follows. The four types of performance cue are organized hierarchically, as in Figure 1: structural, expressive, interpretative, and basic. The sections and subsections of the formal structure provide the upper levels of the hierarchy, with expressive cues further dividing subsections into expressive phrases. Interpretive and basic performance cues are embedded within this hierarchical organization, providing different types of information about critical points of interpretation and technique.

Different musicians are likely to use the same structural cues for a particular piece (although Ginsborg et al., 2006 describe a case where a singer and conductor understood the musical structure slightly differently), and to differ more from one another at lower levels in this hierarchy. The basic performance cues provide the most unique information and at this level the requirements of different performers and different instruments are likely to differ widely. For example, basic performance cues for a cellist include issues of intonation, bowing, and changing string (Lisboa et al., 2004) that are not relevant for a pianist (Chaffin et al., 2002). For solo works, the only performance cues required are those for the individual musician, while for ensemble performance the musicians must also establish shared performance cues to coordinate their actions (Ginsborg et al., 2006)

In learning a new piece, the musician moves up and down the hierarchy, attending to each level of organization and each type of cue in turn at different points in the learning process (Williamon, Valentine \& Valentine, 2002). Experts in other fields approach a new problem, by looking at the "big picture" (Chi, Feltovich \& Glaser, 1981; Glaser \& Chi, 1988; Gobet \& Simon, 1996). Musicians approach the task of learning a new piece in the same way, by getting an overall "artistic image" of how the music should sound (Neuhaus, 1973; Chaffin et al., 2003). During this initial stage, the musician identifies the formal structure of the piece as well as many of the places that will later become expressive, interpretive, and basic performance cues. In later practice sessions, the musician focuses on basic technique and then on interpretation, revisiting each repeatedly as learning progresses. When the piece is ready, attention returns to expressive performance cues during final preparation for a public performance. Ideally, the musician performs with expressive and structural cues in the spotlight of attention with basic and interpretive performance cues in the background, ready to be called upon if needed.

In the studies reviewed here, four types of evidence show that musicians attend to different types of performance cues as their memory for a piece develops and they continue to attend to them dur- 
ing polished performances at the end of the learning process. First, the musicians' spontaneous comments to the video camera taping their practice indicate the issues that are the focus of their problem solving efforts at that moment. Second, the locations of starts, stops and repetitions during practice reveal which aspects of the music the musician was attending to during practice, both those that they were deliberately thinking about as well as those that affected their activities more automatically. Third, tests of recall of the musical score after the final performance indicate how the piece was organized in a performer's memory when it was last played. Fourth, a comparison of bar-to-bar fluctuations in the tempo and dynamics of polished performances indicates which aspects of the performance can be spontaneously altered from one occasion to another.

\section{A CASE STUDY: THE ITALIAN CONCERTO (PRESTO)}

We will illustrate what can be learned about how experienced musical soloists memorize by describing one study of a concert pianist, Gabriela Imreh, learning the Italian Concert (Presto) by J.S. Bach for professional recording as part of an all-Bach CD (Imreh, 1996). [The entire Presto can be heard at http://psychlops. psy.uconn.edu/rchaffin/Italianconcerto(presto).mp3] First we will describe three occasions on which the pianist talked to the camera immediately after a practice performance, describing what she was attending to as she played. Second, transcription of the practice clearly reveal the performance cues that the pianist was thinking about as she practiced and the changes in the kind of cue she attended to as her mastery of the piece developed. Third, recall of the score after the final performance reveals the organization of the music in the pianist's memory at the end of the learning process. Fourth, a comparison of practice performances near the end of the learning process with the performance released on the CD demonstrate the kind of flexibility the pianist was able to introduce into her polished performances.

The pianist had played Bach throughout her career and had taught the Italian Concerto to a student three years before, but had never performed the piece herself before the start of the study. The Presto is of moderate difficulty (Hinson, 1987), is scored in 210 bars in 37 sections, notated in 2/4 time, and lasts for 3-4 minutes at performance tempo. The pianist recorded her practice from the first time she sat down at the piano until the piece was performed without the score at the recording session.

\section{Description of the learning process}

Preparation of the piece took 57 practice sessions, totaling 33 hours 25 minutes, over 10 months including two breaks totaling almost 6 months during which the piece was not practiced (see Table 1). After an initial sight reading through the whole piece, practice began with the pianist working her way through the piece a few sections at a time making fingering decisions and establishing motor memory through repetition. This continued through session 6 , at which point there was a three-day break dur-

\section{Table 1.}

Distribution of practice sessions across 42 weeks, showing mean session duration and mean length and number of practice segments (uninterrupted playing of the score) per session.

\begin{tabular}{|c|c|c|c|c|c|c|}
\hline \multirow[b]{2}{*}{ Session } & \multirow[b]{2}{*}{ Description } & \multirow[b]{2}{*}{$\begin{array}{l}\text { Weeks from } \\
\text { start of practice }\end{array}$} & \multicolumn{2}{|c|}{ Session duration } & \multicolumn{2}{|c|}{ Practice Segments } \\
\hline & & & Total & Mean & $\begin{array}{l}\text { Mean length } \\
\text { (bars) }\end{array}$ & Mean number \\
\hline $1-6$ & Section-by-section & $1-3$ & $6: 20$ & $1: 03$ & 5.4 & 381.7 \\
\hline $7-8$ & First performance from memory & 3 & $2: 18$ & $1: 09$ & 8.0 & 362.5 \\
\hline \multirow[t]{2}{*}{$9-16$} & Developing automaticity & $3-20$ & $5: 32$ & $0: 41$ & 15.5 & 134.5 \\
\hline & BREAK 1 & $5-19$ & & & & \\
\hline 17 & Memorization & 20 & $1: 02$ & $1: 02$ & 47.6 & 60.0 \\
\hline \multirow[t]{2}{*}{$18-24$} & Polishing for first performance & $21-22$ & $4: 13$ & $0: 36$ & 39.3 & 35.5 \\
\hline & BREAK 2 & $23-30$ & & & & \\
\hline $26-27$ & Re-learning & 30 & $0: 55$ & $0: 21$ & 16.3 & 60.5 \\
\hline $28-36$ & Increasing the tempo & $32-36$ & $5: 55$ & $0: 39$ & 21.0 & 93.2 \\
\hline $37-44$ & Polishing for second performance & $37-41$ & $3: 15$ & $0: 24$ & 63.0 & 20.0 \\
\hline $45-57$ & Maintenance & $41-42$ & $3: 55$ & $0: 18$ & (not recorded) & (not recorded) \\
\hline
\end{tabular}


ing which the pianist worked on the first movement. When she returned to the Presto in session 7, work in each session ranged over the entire piece, rather than being limited to a few sections as before. The goal was now to develop the ability to play through the whole piece fluently and session 8 ended with the first practice performance "mostly from memory". The pianist played the piece through without the score for the first time at the end of session 12 to see how well it was memorized before setting the piece aside for nearly four months. Developing fluency continued after the break until, in session 17, she began to systematically practice playing from memory. Another $4 \frac{1}{4}$ hours of practice were needed to get ready for the first public performance after which she put the piece aside again.

When the pianist returned to the piece two months later, she decided that the tempo needed to be faster and put in another seven hours bringing it up to the new tempo. By session 36 she reported, "The mistakes are starting to fade out a little bit... It's coming along" and in session 45, decided that the piece was ready and stopped recording her practice. She played through the piece each day until the recording session two weeks later, however, and in sessions 49 and 50 she recorded six practice performances in order to have a performance on videotape to play to audiences during talks about the research.

\section{Pianist's comments after practice performance}

There were three occasions when the pianist played the piece through from memory and described the performance cues she was using. The first time she did this, in Session 12, the only cues mentioned were structural.

"Probably now the seams [between sections] are quite obvious... It's going to take a while to get through this, but it's good [for me]. Now I have to check each transition [between themes] because each time it's something different. That's the second time, so ... Oh, I confused them."

The next time was in Session 17, and this time structure was hardly mentioned. Now the focus was on basic cues - technical difficulties, fingerings, and patterns of notes.

"Eventually at this level you start to have a sort of map of the piece in your mind and you ... focus on certain places in it. I'll try to tell you... I have a thing in bar 42 where I have to remember to go all the way to the G...I have to concentrate on the fingering in bar 65, the left hand divided between two, four fingers... I have, oh boy, the scale in the left hand at [bar] 124, the two fours in a row... The fingering in $186^{\prime \prime}$.

The third description was at the end of Session 24, the day before the pianist performed the piece in public for the first time. Now the focus was on interpretation; basic cues were hardly mentioned.

"Then I return to very lightly pianissimo. And again, just the left hand $B$ flat (accented), and then I return to pianissimo... And that gives me again room for a nice crescendo in [bar] 86 and on..."

There was almost no mention of expression. This does not mean that the public performance the next day was not expressive. There was plenty of expression built into the automatic actions of the performance. But the pianist was not yet focusing on expression as she played. The first direct mention of expressive performance cues came in a more formal report made after Session 31. The pianist was asked to give some examples of the performance cues she was using. Her reply took the form of a diagram (see Figure 2) in which she marked the performance cues she was using for bars 77-92. Expressive goals were mentioned for the first time in this diagram as expressive performance cues, along with basic and interpretive performance cues. Some bars contained all three. For example, bar 85 contains an expressive cue marked, "start building tension", an interpretive cue labeled, "start crescendo", and a basic cue labeled "left hand leads, pattern changes, more legato". The three cues represent three different ways of thinking about the same point in the music. The different ways of thinking would have been salient at different points in the learning process. In session 17 attention would have been on "Left hand leads...". In session 24, the interpretive performance cue at the same point was referred to as the "nice crescendo in [bar] 86". Finally, in the report of performance cues given after session 31 , the pianist identified the expressive effect of the crescendo with the expressive performance cue, "start building tension".

The pianist's descriptions of what she was attending to in practice provide the first indication that she attended to different types of performance cues at different points in the learning progress. The progression in her comments suggest that she attended first to musical structure, then to basic cues, next to interpretive cues, and finally to expressive cues. We turn now to behavioral data for further evidence supporting this conclusion. 


\section{Performance Cues}
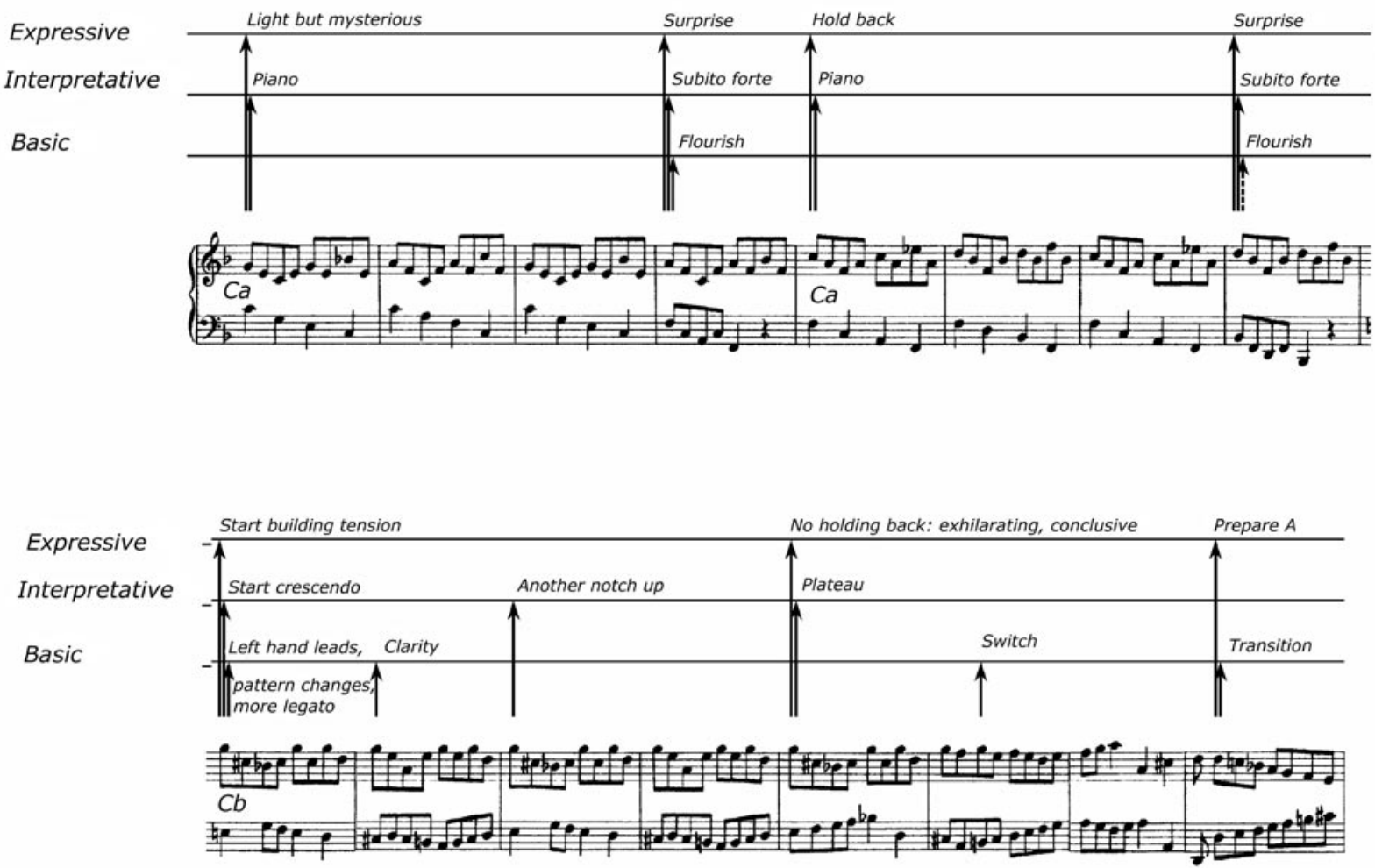

\section{Figure 2.}

The performance cues (represented by arrows) that the pianist reported attending to during practice and performance for bars 77-92

\section{Starts, stops and repeats during practice}

Another source of information about what the pianist was attending to is provided by her practice. Where did she start and stop; which bars were repeated more? Starts, stops, and repetitions provide a revealing behavioral record of what the pianist was thinking about during practice. Decisions are made rapidly and continuously, reflecting the moment-to-moment judgments and decisions of the musician. Starting at a particular location requires attention to the music at that location, as does deliberate stopping. Stopping, when not deliberate, indicates problems. Repetition shows that a passage was singled out for practice.

Figure 3 shows a portion of the practice record for session 9 in which the pianist worked on the same short passage for which we just described the performance cues. The record shows that the starts, stops, and repetitions were not random. For example, some bars were used as starting places more than others. What was special about these bars? The performance cues in Figure 2 provide the answer. The pianist was starting at performance cues. In Figure 3, we see the performance cues being set up as the pianist worked on this passage for the first time. Starting at a particular spot establishes a retrieval cue so that later, simply thinking of that spot in the music is sufficient to initiate playing (Chaffin \& Imreh, 2002; Chaffin et al., 2003). This conclusion is not based solely on the small sample of practice in Figure 3. Performance cues affected practice throughout the 10 months of practice with different types of performance cues affecting practice at different points in the learning process.

Effects of each type of performance cue on practice were identified by transcribing the practice in each session and counting the number of starts, stops, and repetitions for each bar. These three measures served as dependent variables in regression analyses in which the number of performance cues of each type of performance cue reported for each bar were the predictors. Table 2 summarizes the results of these analyses. Most of the effects were positive, indicating that the pianist was starting, stopping or repeating bars containing performance cues significantly more than at other bars not containing cues. Negative effects also indicate that the pianist was paying attention to the type of cue producing the effect but was avoiding 


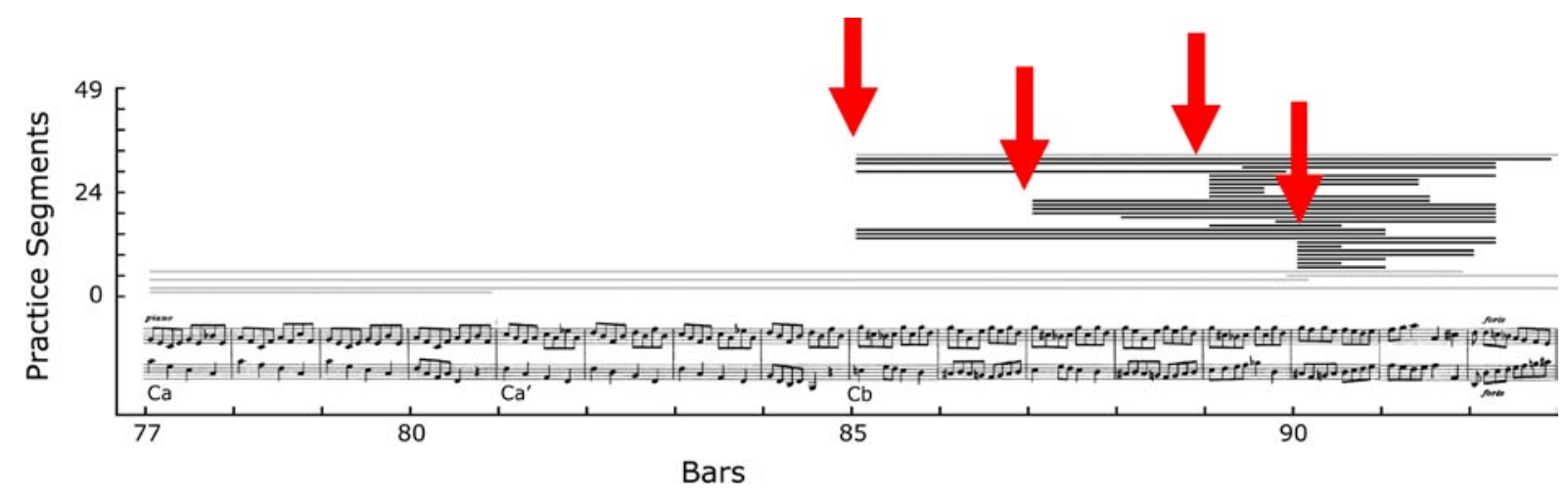

Figure 3.

The record of practice during Session 9 of bars 77-92. The record reads from bottom to top, with each line representing the playing of the music shown below. Each time the pianist stopped and started again the record begins again on the next line up. The starting places correspond with the location of the performance cues for the passage. In Session 9, the pianist was setting up the performance cues by using them as starting places. ${ }^{2}$

\section{Table 2.}

Significant effects $(p<.05)$ of musical structure and performance cues on the frequency of Starts (S), Stops (E) and Repetitions $(R)$ as a function of practice session. Positive effects are listed in blue and capital letters, negative effects in red and lowercase. ${ }^{2}$

\begin{tabular}{|c|c|c|c|c|c|c|c|c|}
\hline \multirow[b]{3}{*}{ Musical Structure } & \multicolumn{8}{|c|}{ Sessions } \\
\hline & $1-6$ & $7-8$ & \multirow[t]{2}{*}{$9-16$} & \multirow[t]{2}{*}{17} & \multirow[t]{2}{*}{$20-24$} & \multirow[t]{2}{*}{$26-27$} & \multirow[t]{2}{*}{$28-36$} & \multirow[t]{2}{*}{$37-50$} \\
\hline & & & & & & & & \\
\hline Begin Section & $S E$ & & $\mathrm{~S}$ & $\mathrm{~S}$ & $\mathrm{~S}$ & $\mathrm{~S}$ & $\mathrm{~S}$ & $\mathrm{~S}$ \\
\hline Ends Section & $\mathrm{R}$ & & & & & & $E$ & \\
\hline Switch & $S E R$ & & & & & & $E$ & $\mathrm{R}$ \\
\hline \multicolumn{9}{|l|}{ Performance Cues } \\
\hline Basic Cue & $\mathrm{S}$ & $S E R$ & $S R$ & $\mathrm{R}$ & & & & $r$ \\
\hline Bar after Basic Cue & $\mathrm{R}$ & $S E R$ & E R & $\mathrm{R}$ & & & & \\
\hline Interpretive Cue & & & $S R$ & & $E$ & $S R$ & & S \\
\hline Bar before Interpretive & & & $\mathrm{R}$ & $\mathrm{S}$ & E R & $\mathrm{R}$ & & \\
\hline Expressive Cue & & & & $\mathrm{S}$ & & & & r \\
\hline Bar before Expressive & & & & & $r$ & $r$ & e $r$ & e \\
\hline Bar after Expressive & & & & & & & e & e \\
\hline R2 Starts & .23 & .22 & .28 & .16 & .08 & .15 & .12 & .11 \\
\hline R2 Stops & .16 & .29 & .17 & .05 & .07 & .06 & .14 & .07 \\
\hline R2 Repeats & .10 & .44 & .42 & .20 & .06 & .18 & .10 & .18 \\
\hline
\end{tabular}

stopping, starting, or repeating them. Negative effects occurred mainly for expressive cues and indicate that changes of expressive intention were practiced by playing through them without stopping.

The practice data summarized in Table 2 showed that the pianist was thinking about the formal structure throughout the learning process and attended to each type of performance cue in turn. The progression was similar to the one we have already seen in the comments: first basic, then interpretive, then expressive, with effects of structure throughout. We next describe this pattern of effects in more detail.

\section{Formal structure}

The pianist started and/or stopped at section boundaries (beginnings and ends of sections) more often than at other locations in every session set except sessions 7-8. The effects show that the pianist was thinking of the structure throughout, suggesting that she used the hierarchical organization as a retrieval structure 
(Chaffin \& Imreh, 2002; Miklaszewski, 1989, Williamon \& Valentine, 2002). In sessions 7-8, the pianist needed to practice putting sections together for the first time after the section-by-section practice of sessions $1-6$ and avoided starting and stopping at section boundaries in order to rehearse the transitions between sections.

Attention to musical structure is also evident in the practice of switches, which are points of structural ambiguity where the same passage occurs at different points in the piece. Switches were a focus of attention at the beginning and end of the learning process. In sessions 1-6, switches received more starts, stops, and repetitions than other bars. Switches were not singled out for attention again until sessions 28-36, when playing stopped at switches once again. We have already quoted the pianist's comment about the difficulty of remembering "which way the switch would go". When retrieval from memory did not keep up with the new, faster tempo in sessions 28-36, it was at switches that playing was interrupted. The solution was more practice of switches and this took place in sessions 37-50 when switches were once again repeated more than other features.

\section{Performance cues}

The progression in the effects of performance cues (first basic, then interpretive, then expressive; see Table 2) took a different form for each measure, reflecting differences in the factors responsible for starting, stopping, and repeating. Changes in where playing starts reflect changes in the mental landmarks for the piece. Changes in where playing stops also reflect changes in landmarks as well changes in the problems interfering with fluent performance. Changes in which performance cues are repeated reflect changing goals for practice.

The progression was clearest for stops. First, in sessions 7-8 and 9-16, as the pianist developed the ability to play through the entire piece, she stopped at basic cues more often than at other locations. The memory for what she needed to do was not coming to mind quickly enough and she stopped to make sure that crucial details of technique were executed as planned. Then, in sessions 20-24, as she prepared for the first performance, she stopped at interpretive cues, indicating that it was now interpretive gestures that were not coming to mind quickly enough. Finally, in sessions 28-36 and 37-50 during the final polishing, it was expressive cues that affected stops. The effects were negative, indicating that the pianist did not stop at expressive cues, reflecting the fact that to practice expression it is necessary to play through emotional turning points without interruption.
There was a similar progression for starts during sessions 1-17 but not thereafter. Practice segments started at basic performance cues in sessions 1-6 and 7-8 as she practiced the piece in sections and put it together for the first time. Next, as automaticity developed in sessions 9-16, interpretive cues were added to basic. Then, when she memorized the piece in session 17, she started at interpretive and expressive cues, shifting her attention to the main musical turning points. The progression did not continue in later sessions. Relearning the piece again in sessions 26-27 after a 3-month break, starts were once again at interpretive cues and this continued in the final polishing in sessions 37-50.

The progression of effects for repeats was more complex. A progression from basic to interpretive to expressive was interrupted at two points by a return to the practice of basic cues. Initially, the effects were similar to those for starts: passages containing basic cues were repeated more than others in sessions 1-6 and 7-8 and then basic and interpretive cues were repeated more in sessions $9-16$. In session 17 , however, effects for starts and repetitions diverged; as the pianist practiced performing from memory for the first time effects of interpretive cues disappeared and basic cues re-emerged. The progression resumed in sessions 20-24, as she prepared for her first public performance: interpretive cues were repeated more and expressive cues less. These effects continued in sessions 26-27, as the piece was relearned after a 3-month break and then practice of interpretive cues disappeared during further polishing of the piece in sessions 28-36, leaving expressive cues as the main focus of attention. Finally, in sessions 37-50 the negative effect of expressive cues was accompanied by a negative effect for basic cues. In the final polishing of the piece, the pianist apparently practiced the retrieval cues for both expression and technique by playing fluently through them without interruption.

In sum, the pattern of effects indicate that, in general, the pianist attended first to basic, then to interpretive, and finally to expressive cues with starts, stops, and repetitions showing the progression in different ways. The progression was simplest for stops (basic in sessions 7-16, interpretive in 20-24, expressive in 28$50)$. For starts the same progression was evident until the piece had been memorized in session 17 (basic in 1-16, interpretive in 9-17, expressive in session 17). For repeats, the pattern was interrupted by the reappearance of effects of basic cues in sessions 17 and 37-50 (basic in 1-17, interpretive in 9-16 and again in 20-27, expressive in 20-50). Despite the differences, 
each measure showed basic performance cues being practiced earlier and expressive cues later.

The practice data provide behavioral confirmation of the pianist's report that she practiced performance cues and that she focused on expressive cues in her final preparation for performance. They do not, however, show that the pianist continued to think about performance cues during performance. For evidence of this point we turn to her recall of the score after the final performance.

\section{Effects of performance cues on recall of the score}

Free recall reflects the organization of information in memory. Recall of an ordered series is generally better for the first item in the series and declines with each succeeding item (Broadbent, Cooper, \& Broadbent, 1978; Raaijmakers \& Shiffrin, 1981; Roediger \& Crowder, 1976). Serial position effects are thus a reflection of how information is organized in memory. Performers generally report that during the final preparation for performance, they focus more on musical expression and less on technique. If these reports are accurate, we would expect to find serial position effects for structural boundaries and expressive and interpretive cues. Better recall of the score at points where these cues are reported would indicate that they functioned as retrieval cues. Declining recall in following bars would suggest that memory was organized in associative chains starting at each retrieval cue.

Twenty-seven months after the recording session the pianist in the Presto study was unexpectedly asked to write out the score from memory. Her memory was remarkably good, 65\% accurate (Chaffin \& Imreh, 1997; Chaffin et al., 2002, p. 212). More interesting, though, were the effects of the different kinds of performance cues.

The proportion of notes correctly recalled in each bar provided a measure of the probability of recall. (Table 3 shows the effect of serial position with respect to each type of performance cue on recall of the score.
Chaffin \& Imreh, 2002; Chaffin et al., 2002, p. 214). The serial position effects tell us that the pianist's memory was organized primarily in terms of formal structure and expressive cues, even after a more than two-year absence from performing the piece. Recall was best for bars marked by structural boundaries and tapered off with each successive bar. Expressive and interpretive cues produced similar effects, although the effect for interpretive cues was not significant. Basic cues, on the other hand, produced the opposite effect. Recall was worse for the bar containing the cue and improved over the next three bars. The effect suggests that the role of basic cues was different from that for expressive cues. Basic cues represent details about planned movements that were not called for in the written recall task and that apparently interfered with it. Structural and expressive cues, in contrast, were linked to the conceptual representation of the piece that was required for writing out the score.

The main landmarks in her memory for the piece more than two years later were the structural and expressive cues. The serial position effects for these cues support the pianist's report that during the final performance she was thinking mainly about musical expression with basic and interpretive performance cues on the fringes of her awareness, available in case things went wrong. There is, however, another possible explanation. The finished performance could have been entirely automatic. On this view, performance cues functioned as retrieval cues as a result of extended practice but did not otherwise control the performance. To evaluate the pianist's claim that she used structural and expressive cues to monitor and direct her performance, we turn next to the polished performances at the end of the learning process and in the recording studio.

\section{Tempo variation during performance}

For evidence that performance cues guide and control polished performance, we need to compare their ef-

\section{Table 3.}

Probability of correctly recalling the score decreased with distance from section boundaries and expressive cues and increased with distance from basic cues

\begin{tabular}{lccccc}
\hline & \multicolumn{5}{c}{ Serial position: Distance from cue in number of bars } \\
\cline { 2 - 6 } Type of Performance Cue & $\mathbf{1}$ & $\mathbf{2}$ & $\mathbf{3}$ & $\mathbf{4}$ & $\mathbf{5 - 8}$ \\
\hline Structural Boundary & .97 & .90 & .87 & .69 & .28 \\
Expressive & .85 & .85 & .74 & .43 & .00 \\
Basic & .68 & .77 & .78 & .77 & .46 \\
Interpretive & .75 & .78 & .61 & .00 & \\
\hline
\end{tabular}



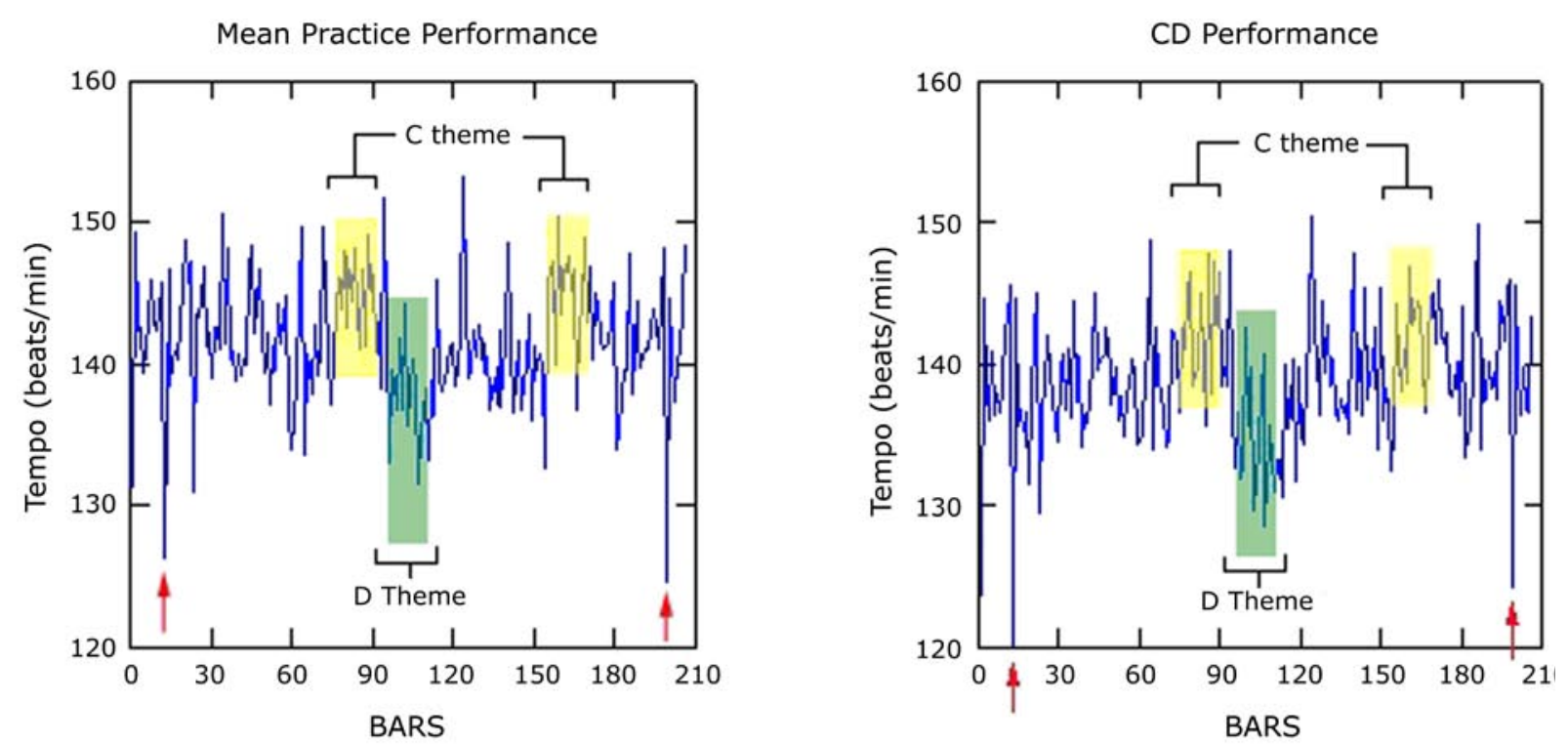

\section{Figure 4.}

Profiles of tempo in beats/min, plotted across bars for mean practice and the CD performance (last three bars omitted for tempo and first and last bars omitted), showing the locations of two of the downward octave jumps and ascending 8th note scales (indicated by red arrows) and the $C$ and $D$ themes (indicated by highlighting and brackets).

fects on different performances. Systematic differences between performances attributable to performance cues would support the proposals that these cues are responsible for the differences between performances that musicians commonly report, and that skilled performance involves the strategic management of the variability inevitable in any activity (Latash, Scholz \& Schoner, 2002; Todorov \& Jordan, 2002; Van Orden et al., 2003). On the other hand, the absence of statistically significant differences between performances would suggest that any differences that do occur are not a product of systematic control process but simply reflect the random variability that pervades any activity. On this account, the impression of many performers that each performance is unique is an illusion; the differences are not a product of artistic inspiration or the skilled management of variability but of random noise. On this view, performers remember the random variations that happen to be musically significant and forget those that are not (Chaffin et al., 2006).

We will illustrate the type of analysis needed to evaluate these claims by comparing the pianist's performance of the Presto in the recording studio, released on $\mathrm{CD}$, with the mean of seven polished performances in the practice studio in the two weeks leading up to the final performance. The comparison approximates the common situation of a pianist giving repeat performances in different venues. Differences would show that the professionally important CD performance differed from the most reliable measure available of the pianist's intended performance in the practice sessions that preceded it. The absence of live audiences for all of the performances lessens the chance of finding differences as does averaging across practice performances. Finding differences between these performances would suggest, therefore, that differences are likely any time the same piece is performed repeatedly. (Differences between the seven practice performances are reported by Chaffin et al., 2006. The present comparison has not been reported elsewhere and provides a more conservative test of the prediction of differences between repeated performances.)

We might expect attention to basic performance cues to be reflected in slower tempi, to allow time to monitor the details of execution represented by these cues. Predictions for the effects of expressive and interpretive performance cues are more complex because their effects depend on the nature of the musical gesture intended. The predominant feeling evoked by the Presto is of headlong, rushing forward. For a piece of this sort, we expected that expressive cues, representing higher levels of emotional intensity (as reported by the pianist) would be associated with faster tempi. For interpretive cues, we empirically identified four additional musical gestures by identifying fluctuations in tempo that were consistently related to features of the music. We then looked for differences between performances in the effects of the gestures. All of the musical gestures identified involved features that occurred at multiple points in the piece. Any ef- 
fects cannot, therefore, be readily attributed to the idiosyncratic playing of a single bar. Rather, significant effects would indicate that a musical gesture involved consistent changes at multiple points in the piece. Likewise, differences between performances in the effect of a gesture would reflect consistent differences in the same direction at multiple points.

\section{Description of the performances}

As required by the score and by Baroque performance practice, the tempo was fast and variation minimal (Mean $=141.5$ and 139.0 beats $/ \mathrm{min}$ for the practice and $C D$ performances respectively; $S D=4.4$ and 4.6 beats/min respectively). The pianist played a mean of approximately 14 notes per second throughout the entire piece, while the standard deviations indicated that the average variation in tempo was well below the $20 \mathrm{~ms}$ threshold required for detection (Clarke, 1989). Although values for the two performances were very similar, tempo was reliably faster in the practice performances, $t(207)=12.80, p<.001$, something that the pianist had anticipated in session 42 when she noted that she might slow down for the CD performance to "make it sound easy" (Chaffin et al., 2002, p. 154).

\section{Identification of musical gestures}

The tempo profiles for the $C D$ and mean practice performances, shown in Figure 4, contain marked similarities $(r=.79)$. For example, there were sharp down and up spikes (indicated by red arrows in Figure 4) at the beginning (bar 13-14) and end (bar 199-200). These spikes coincide with the beginning of the $A$ theme which is introduced by a downward octave jump followed by an ascending scale of eighth notes (see Figure 5). These two musical features contribute to the predominant feeling that the Presto seems to evoke of headlong, forward motion. The downward jump seems to evoke the feeling of leaping downward, while the upward scale gives an impression of rushing back up again. These musical images were accentuated by the pianist. By prolonging the first note of the jump (downward spikes), she seemed to reinforce the sensation of leaping down and the impact of landing. By compressing the time taken by for the upward scale (upward spikes), she emphasized the feeling of rushing upward. The $A$ theme returns repeatedly throughout the piece, and the repetition of these two gestures is responsible for many of the upward and downward spikes in both performances. A third musical gesture was responsible for some of the large-scale

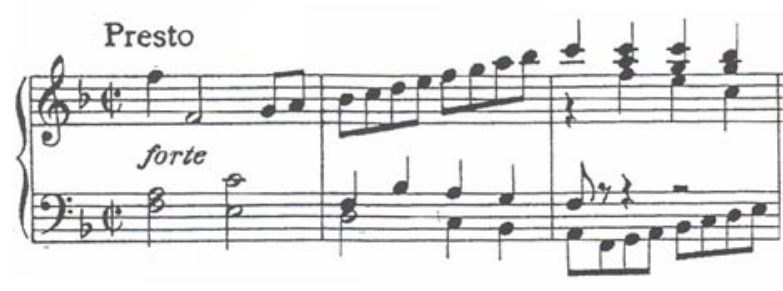

\section{Figure 5.}

Score of bars 1-3 showing musical features that elicited two of the pianist's interpretive gestures: the octave jump down in bar 1 and the ascending 8th note scale in bar 2 .

wave structure evident in both performances in Figure 4. Two sections containing the light, dancing $C$ theme (bars 77-92 and 155-166; highlighted and indicated by brackets in Figure 4) were faster while the complex fugue in the $D$ theme that marks the center of the piece (bars 104-112) was slower.

An additional gesture was identified on the basis of the pianist's reports of her decisions about phrasing. When these were compared with the fluctuations in tempo, it was evident that tempi were slower in bars where the pianist reported beginnings of phrases. These musical gestures are listed in Table 4 along with the other predictors used in the analysis of tempo (basic and expressive performance cues, expressive intensity, section bounds, switches and technical difficulties). Table 4 also shows the source of each predictor (pianist's report or our visual inspection of the correspondences between the profiles and musical score just described), the number of bars in which each gesture or musical feature occurred, and the range of values used to code it. All gestures occurred in multiple locations in the piece so their effects were unlikely to be due to the idiosyncratic playing of a single bar.

\section{Factors affecting performance}

Effects of the predictors on the two performances are summarized in Table 5 (left and middle panels). Positive effects indicate increases in tempo; negative effects indicate decreases. The table also summarizes differences between the mean practice and CD performances (right hand panel). The regression coefficients in the right hand panel of Table 5 represent effects in the CD performance that were not present in mean practice performance.

The most important result for our purposes was that there were differences between the $C D$ and practice performances attributable to expressive and to basic performance cues. The differences support the proposal that performance cues were used to control the performances. Passages where the pianist reported 


\section{Table 4.}

Description of predictors used in analysis of tempo indicating how each was identified (source), the number of bars involved ( $\max 210$ ) and the range of values used to code presence/absence in a bar.

\begin{tabular}{|c|c|c|c|c|}
\hline & Description & Source & $\begin{array}{l}\text { Number of bars } \\
\text { involved }\end{array}$ & Values coded \\
\hline \multicolumn{5}{|l|}{ Performance cues } \\
\hline $\begin{array}{l}\text { Expressive performance } \\
\text { cues }\end{array}$ & $\begin{array}{l}\text { Change in expressive } \\
\text { intention }\end{array}$ & Pianist & 71 & $0-2$ \\
\hline Expressive intensity & $\begin{array}{l}\text { Level of expressive } \\
\text { intensity }\end{array}$ & Pianist & 210 & $1-5$ \\
\hline Basic performance cues & $\begin{array}{l}\text { Attention to technique } \\
\text { during performance }\end{array}$ & Pianist & 125 & $0-3$ \\
\hline \multicolumn{5}{|l|}{ Musical structure } \\
\hline Section begins or ends & $\begin{array}{l}\text { First and last bars of } \\
\text { subsections }\end{array}$ & Pianist & 37 & 0,1 \\
\hline Switches & $\begin{array}{l}\text { Similar musical material } \\
\text { repeats }\end{array}$ & Pianist & 42 & $0-3$ \\
\hline Technical difficulties & $\begin{array}{l}\text { Technique required } \\
\text { repetition during practice }\end{array}$ & Pianist & 126 & 0,1 \\
\hline \multicolumn{5}{|l|}{ Interpretive Gestures } \\
\hline Octave jump down & $\begin{array}{l}\text { Octave jump before or } \\
\text { at start of } A \text { theme }\end{array}$ & Investigator & 11 & 0,1 \\
\hline 8th note upward scale & $\begin{array}{l}\text { Octave scake of } 8 \text { th notes } \\
\text { before or after Jump:A }\end{array}$ & Investigator & 15 & 0,1 \\
\hline Theme & $\begin{array}{l}\text { Ranking of tempo of } \\
A, B, C \& D \text { themes }\end{array}$ & Pianist/Investigator & 210 & $1-4$ \\
\hline Phrasing & Starts of phrases & Pianist & 188 & $0-7$ \\
\hline
\end{tabular}

that she intended to play with more expressive intensity were marked by faster tempi. The effect was present in both practice and $C D$ performances but was larger in the CD performance, $F(1,192)=26.14$, $p<.01$. The pianist apparently used faster tempi to convey more intense musical feelings (cf. Juslin, 2000, 2003) and exaggerated this gesture more in the $C D$ than in the practice performance. The slightly slower tempo used in the CD performance may have allowed more scope for expressive variation (Repp, 1995). The second difference was in the slowing in bars before basic performance cues which was more pronounced in the mean practice than in the $C D$ performance, $F(1,192)=28.49, p<.01$. In six of the seven practice performances the pianist was trying to produce a videorecording to be played to professional audiences during talks about the research. She was concerned with giving a note-perfect performance and commented that all of the performances sounded "cautious" as a result. In the recording studio, in contrast, she could afford to take more risks because mistakes could be removed by editing. Slowing in bars before basic performance cues in the practice performances was, therefore, probably due to taking a little more time to ensure that technical details were executed correctly. In summary, the differences between the two performances suggest that the pianist altered her performance in the recording studio by playing more expressively and less cautiously and that these adjustments were achieved through the use of performance cues.

The differences between the $C D$ and practice performances are difficult to detect but may be discernable in the overall "feel" of the performance. Readers can judge for themselves for measures 184-195 where the CD performance seems to us slightly more expressive but not noticeably faster than a representative practice performance of the same passage. Sound files for these selections can be found at http://csa.uconn. edu/research/public/mm184CD.mp3 and http://csa. uconn.edu/research/public/mm184practice.mp3.

There were no differences between the two performances in the interpretive gestures. Effects of all four gestures were significant for both the $C D$ and practice performances, confirming the description of these gestures given above. First, the pianist's accentuation of the downward octave jump at the start of the $A$ theme was reflected in a negative (slowing) effect. Second, the accentuation of the upward rush of the ascend- 
Table 5.

Regression coefficients and $R 2$ for the effects of musical gestures, performance cues, and basic features on the mean of practice performances in sessions 42-50 and the CD performance and differences between the two.

\begin{tabular}{|c|c|c|c|}
\hline & $\begin{array}{l}\text { Mean practice } \\
\text { performance }\end{array}$ & CD performance & $\begin{array}{l}\text { Difference of } \mathrm{CD} \text { from } \\
\text { mean practice performance }\end{array}$ \\
\hline Predictor Variable & Tempo & Tempo & Tempo \\
\hline Mean practice performance & & & $1.058 * * *$ \\
\hline \multicolumn{4}{|l|}{ Expressive performance cues } \\
\hline Expressive cue & 0.411 & 0.783 & 0.151 \\
\hline Bar before expressive cue & 0.900 & 0.741 & -0.127 \\
\hline Expressive intensity & 0.148 & $0.527 * *$ & $0.170 * *$ \\
\hline \multicolumn{4}{|l|}{ Basic performance cues } \\
\hline Basic cue & $-0.764 \sim$ & -0.363 & 0.233 \\
\hline Bar before basic cue & $-1.502 * * *$ & -0.546 & $0.538 *$ \\
\hline \multicolumn{4}{|l|}{ Musical Structure } \\
\hline Begin section & 0.097 & -0.616 & -0.341 \\
\hline End section & $-1.767^{*}$ & $-1.459 \sim$ & 0.248 \\
\hline Switch & -0.052 & -0.477 & -0.197 \\
\hline Bar before switch & $1.181^{* *}$ & $1.238^{*}$ & -0.042 \\
\hline \multicolumn{4}{|l|}{ Technical difficulties } \\
\hline Technical difficulties & -0.422 & 0.135 & 0.287 \\
\hline \multicolumn{4}{|l|}{ Interpretive gestures } \\
\hline Octave jump down & $-5.812 * * *$ & $-6.255 * * *$ & 0.131 \\
\hline $8^{\text {th }}$-note upward scale & $5.019 * * *$ & $5.576 * * *$ & -0.031 \\
\hline Theme & $-1.633 * * *$ & $-1.457 * * *$ & 0.178 \\
\hline Phrasing & $-1.759 * *$ & $-1.956 * *$ & 0.010 \\
\hline $\mathrm{R}^{2}$ & $0.50 * * *$ & $0.45^{* * *}$ & $0.92 * * *$ \\
\hline
\end{tabular}

$* p<.05, * * p<.01, * * * p<.001$

+ Significance levels for predictors based on interaction of predictor with performance in a $2 \times 14$ mixed ANOVA. See text for explanation.

ing scale resulted in a positive (accelerating) effect on tempo. Third, the differences between the faster $C$ theme and the slower $D$ theme were significant in both performances. Fourth, beginnings of phrases were marked by slower tempi in both performances. The use of a short pause or "breath" to mark the beginning of a new phrase is a common interpretive device (De Poli, Roda \& Vidolin, 1998; Repp, 1998).

There were also no differences between the two performances in the effects of musical structure. The slowing at the ends of sections that occurred in both performances is a common expressive device (Clarke, 1999, Gabrielsson \& Lindström, 2001; Palmer, 1989, 1997). The effect was statistically reliable only in the mean practice performance, but did not differ significantly from the trend in the same direction in the CD performance.

The faster tempo in bars before switches can be attributed to the tendency to play faster in difficult passages. The pianist reported that keeping track of the switches was what made the Presto hard to play from memory. The tendency to overcome difficulties by playing faster (and louder) is very familiar to musicians, although it has not, to our knowledge, been explored by psychologists. It is possible that increasing tempo, amplitude, or force helps overcome inertia in the motor system (Stins \& Michaels, 1999). It is interesting to compare the effects of switches and basic performance cues. Basic cues included a subset of switches - those most likely to give problems. In spite of the overlap, the effects on tempo were different. Tempo increased before switches and decreased before basic cues. At basic cues, the pianist was thinking about the upcoming difficulty and slowed down accordingly. Switches that were not marked by basic cues, in contrast, were places where the pianist did not anticipate problems. In these cases, she apparently relied instead on the automaticity of motor memory, increasing the tempo to help push through any residual difficulty. 


\section{CONCLUSION}

Solo recitals in the Western classical music tradition place extraordinary demands on the performer. Performances must be practiced to the point that they can be delivered automatically in order to ensure reliability under the pressures of the concert stage. At the same time, the performance must remain fresh and flexible enough to communicate emotionally with the audience and permit recovery from inevitable mistakes. We suggest that the integration of automatic motor performance and cognitive control needed to provide this flexibility is achieved through the practice of performance cues. Use of performance cues is an attentional strategy that maintains conscious control of a highly automated performance and provides the musical spontaneity that is valued by both performers and audiences. Spontaneity is a byproduct of musicians' ability to use performance cues to adapt a highly prepared performance to the requirements and opportunities of each performance.

When a performer has to think mostly of basic cues dealing with matters of technique, the possibilities for musically creative variation are limited. When a performer is focused on interpretive cues and is thinking about what the music sounds like, the opportunities for creativity are greater but still limited. The goal of performance is to evoke musical feelings and this is best achieved when the performer focuses on expression. An expressively spontaneous performance is, therefore, most likely when the performer is focusing on expressive cues and the musical structure that supports them. This allows the artist to adjust the performance to the unique opportunities and demands of the occasion to achieve the maximum possible impact on the audience.

We base this account of how a performance is prepared on longitudinal case studies of experienced soloists preparing for performance (Ginsborg et al., 2006; Lisboa et al., 2004; Noice et al., in press) which we have illustrated here with a pianist learning the Presto (Chaffin \& Imreh, 2001, 2002, Chaffin et al., 2002; Chaffin et al., 2003, 2006). The analysis was based initially on the performer's self-reports after practice performances. We then looked at behavioral evidence to test her account. The pianist's spontaneous descriptions of what she was attending to during practice indicate that during her first practice performance without the score in session 12 she was focused on structure, that the next time she played from memory, in session 17 , she was thinking mostly about basic cues, and that by session 24, when she was ready for her first public performance, she was attending mostly to interpretive cues. Only when preparation was almost complete, between sessions 31 and 32, were expressive cues mentioned explicitly for the first time. The practice data showed a similar progression with practice focusing first on basic, then on interpretive, and finally on expressive cues, with musical structure influencing practice throughout.

The fact that the pianist paid more attention to expressive cues in later practice sessions is suggestive, but does not necessarily prove that expression was the main focus of attention during performances. Practice may have been designed to ensure that actions elicited by expressive cues occurred automatically during performance. The conclusion that the pianist was attending to expressive cues during performance is, however, supported by two additional types of evidence: effects of expressive cues on recall of the score more than two years later and differences between performances in the effects of expressive cues.

First, expressive and structural cues provided the main landmarks of the pianist's memory for the piece two years later, suggesting that these cues had also served as landmarks when she last played the Presto. Second, there was a small but statistically reliable difference in the effects of expressive and basic cues in the $C D$ performance compared to practice performances in the days leading up to the recording session. The pianist increased the tempo in passages where she wanted to increase expressive intensity, and did so more in the $C D$ than in the practice performances. The pianist also slowed the tempo slightly approaching basic performance cues where some point of technique required attention during performance. This effect was larger in the practice than in the CD performance and probably reflects the pianist's concern with producing a note-perfect performance in these sessions. The effects of expressive and basic performance cues on polished performances, thus, support the pianist's report that she attended to expressive cues during performance. The differences between performances support our claim that experienced performers use performance cues to monitor and control the highly practiced, automatic motor sequences developed during the long months of practice. Additional research is needed to understand how planned use of performance cues described here relates to the incremental planning during performance described by Palmer and Pfordresher (2003). The idea that event retrieval relies on metrical similarity and serial proximity may help in understanding why some musical decisions 
made during practice become performance cues while others do not.

Concert soloists provide an interesting test of the principles of expert memory (Ericsson \& Kintsch, 1995) because they make their living performing from memory. Like expert memorists in other fields, the concert pianist in the study we have described engaged in extended practice of a retrieval scheme to ensure that recall occurred rapidly and automatically. This reliance on an explicit, conceptual memory is somewhat surprising, given the importance of implicit, motor and auditory memory in piano performance. However, the pianist went to great lengths to ensure that she could rely on an explicit, conceptual memory. The formal structure of the music provided a hierarchical retrieval structure, organized into sections and sub-sections, with expressive phrases containing basic and interpretive performance cues making up the bottom levels (Figure 1). The pianist engaged in prolonged practice to bring the operation of this retrieval scheme up to the pace of the motor performance. This explicit, conceptual representation allowed her to focus on expressive goals during performance, while also keeping track of where she was so that the performance would unfold as planned. If things did begin to go wrong, the conceptual representation provided a means to recover.

This study, and other case studies like it, extends the principles of expert memory from domains that rely almost entirely on explicit memory (e.g., for material such as digit strings, to a performing art where it might be possible to rely on automatic, implicit motor skills in place of explicit memorization. The experienced musicians we have studied supplement their implicit memories of motor sequences with explicit conceptual memories that provide them with a mental map that is used to monitor and modify the highly practiced motor sequences. This combination of explicit and implicit memory may be a hallmark of expertise in domains such as musical performance that require high levels of both motor dexterity and aesthetic sensibility.

\section{Notes}

${ }^{1}$ It is this smooth integration of retrieval that Ericsson and Kintsch (1995) refer to as "long-term working memory.

2 The analyses summarized here are similar to those reported by Chaffin \& Imreh (2002) in not separating practice into two types (work vs runs) as in Chaffin et al., (2002), but are similar to the latter in dividing sessions into 8 groups. The analyses are different from previous reports in including only musical structure and performance cues as predictors.

\section{Author Notes}

We would like thank Gabriela Imreh for contributing both the ideas on which the research was based and the data to test them, Mary Crawford for helpful discussions, Colleen Chen and Anthony Lemieux for work on the tempo measurements, Ben Chaffin for programming help, and for work on the practice data: Ellie Corbett, Jennifer Culler, Elizabeth Dohm, Helene Govin, Julie Konik, Amelia McCloskey, Sandra Paez, Alethea Pap, and Aaron Williamon.

\section{References}

Broadbent, D.E., Cooper, P.J., and Broadbent, M.H. (1978). A comparison of hierarchical matrix retrieval schemes in recall. Journal of Experimental Psychology: Human Learning and Memory, 4, 486-497.

Chaffin, R., and Imreh, G. (1997). "Pulling teeth and torture": Musical memory and problem solving. Thinking and Reasoning: Special Issue on Expert Thinking, 3, 315-336.

Chaffin, R., Imreh, G. and Crawford, M. (2002). Practicing perfection: Memory and piano performance. Mahwah, NJ: Lawrence Erlbaum Associates. Www Chaffin, R. and Imreh, G. (2001). A comparison of practice and self-report as sources of information about the goals of expert practice. Psychology of Music 29, 39-69.

Chaffin, R. and Imreh, G. (2002). Practicing perfection: Piano performance as expert memory. Psychological Science, 13, 342-349. $\mid \mathrm{www}$

Chaffin, R., Imreh, G., Lemieux, A., and Chen, C. (2003). "Seeing the big picture": Piano practice as expert problem solving. Music Perception, 20, 461485.

Chaffin, R., Lemieux, A., and Chen, C. (2004) "It's different each time I play": Why highly polished performances vary. In S. D. Lipscomb, R. Ashley, R. O. Gjerdingen and P. Webster (Eds.) Proceedings of the $8^{\text {th }}$ International Conference on Music Perception and Cognition. Adelaide, Australia: Causal Productions.

Chaffin, R., Lemieux, A., \& Chen, C. (2006). Spontaneity and creativity in highly practiced performance. In I. Deliège \& G.A. Wiggins. Musical creativity: Multidisciplinary research in theory and practice (pp. 200-218). London: Psychology Press.

Chase, W.G., and Ericsson, K.A. (1982). Skilled and working memory. In G.H. Bower (Ed.), The psychology of learning and motivation 16: 1-58. New York: Academic Press. 
Chase, W. G., \& Simon, H. A. (1973). The mind's eye in chess. In W. G. Chase (Ed.), Visual information processing (pp. 215-281). New York: Academic Press.

Chi, M. T. H., Feltovich, P. J., \& Glaser, R. (1981). Categorization and representation of physics problems by experts and novices. Cognitive Science, 5, 121-125.

Clarke, E. (1999). Rhythm and timing in music. In: D. Deutsch (Ed.), The Psychology of Music (pp. 473500). San Diego, CA: Academic Press.

Clarke, E. (1989). The perception of expressive timing in music. Psychological Research, 51, 2-9

Cooke, J. F. (1999). Great pianists on piano playing: Godowsky, Hofmann, Lhévinne, Paderewski and 24 other legendary performers. Toronto: Dover. (originally published 1913, expanded edition published 1917)

DePoli, G., Roda, A. and Vidolin, A. (1998). Note-bynote analysis of the influence of expressive intentions and musical structure in violin performance. Journal of New Music Research, 27, 293-321.

Ericsson, K. A. and Kintsch, W. (1995). Long-term working memory. Psychological Review, 10, 211-245. Www

Ericsson, K. A., and Oliver, W. L. (1989). A methodology for assessing the detailed structure of memory skills. In A. M. Colley, and J. R. Beech (Eds.), Acquisition and performance of cognitive skills (pp. 193-215). Chichester: Wiley.

Gabrielsson, A. (1999). The performance of music. In Deutsch D. (Ed.), The psychology of music (2nd Ed.) (pp. 579-602). San Diego: Academic Press.

Gabrielsson, A. and Lindström, E. (2001). The influence of musical structure on emotion. In P. N. Juslin and J.A. Sloboda (Eds.), Music and emotion: Theory and research. New York: Oxford University Press.

Ginsborg, J., Chaffin, R. \& Nicholson, G. (2006). Shared performance cues in singing and conducting: A content analysis of talk during practice. Psychology of Music, 34, 167-194.

Gilden, D.L. (2001). Cognitive emissions of $1 / \mathrm{f}$ noise. Psychological Review, 108, 33-56. |WWw

Glaser, R., \& Chi, M. (1988). Overview. In M. Chi, R. Glaser, \& M. Farr (Eds.), The nature of expertise (pp. xv-xxviii). Hillsdale, NJ: Erlbaum.

Gobet, F., \& Simon, H. A. (1996). The roles of recognition processes and look-ahead search in timeconstrained expert problem solving: Evidence from grand-master-level chess. Psychological Science, 7, 52-55.

Hallam, S. (1995a). Professional musicians' approaches to the learning and interpretation of music. Psychology of Music, 23, 111-128.
Hallam, S. (1995b). Professional musicians' orientation to practice: Implications for teaching. British Journal of Music Education, 12, 3-19.

Halpern, A. R., and Bower, G., H. (1982). Musical expertise and melodic structure in memory for musical notation. American Journal of Psychology, 95, 3150.

Hinson, M. (1987). Guide to the Pianist's Repertoire. Bloomington: Indiana University Press

Imreh, G. pianist. (1996). J.S. Bach [CD]. New York: Connoisseur Society.

Imreh, G. and Chaffin, R. (1996/97) Understanding and developing musical memory: The views of a concert pianist and a cognitive psychologist, American Music Teacher, 46, (3): 20-24, 67.

Juslin, P.N. (2000). Cue utilization in communication of emotion in music performance: Relating performance to perception. Journal of Experimental Psychology: Human Perception and Performance, 26, 1797-1813. Www

Juslin, P.N. (2003). Communication of emotions in vocal expression and music performance: Different channels, same code? Psychological Bulletin, 129, 770-814 [WwW]

Krampe, R.T. \& Ericsson, K.A. (1996). Maintaining excellence: Deliberate practice and elite performance in young and older pianists. Journal of Experimental Psychology: General, 25, 331-359. WWW

Latash, M. L., Scholz, J. P., \& Schoner, G. (2002). Motor control strategies revealed in the structure of motor variability. Exercise and Sports Science Reviews, 30, 26-31. Www

Lisboa, T., Chaffin, R., Schiaroli, A.G., Barrera, A. (2004). Investigating practice and performance on the cello. In S. D. Lipscomb, R. Ashley, R. O. Gjerdingen and P. Webster (Eds.), Proceedings of the $8^{\text {th }}$ International Conference on Music Perception \& Cognition, Evanston, IL, 2004. Adelaide, Australia: Causal Productions.

Mach, E. (1991). Great contemporary pianists speak for themselves. New York: Dover.

Mandler, G., and Pearlstone, Z. (1966). Free and constrained concept learning and subsequent recall. Journal of Verbal Learning and Verbal Behavior, 5, 126-131.

Miklaszewski, K. (1989). A case study of a pianist preparing a musical performance. Psychology of Music, 17, 95-109.

Miller, G. A. (1956). The magical number seven, plus or minus two: Some limits on our capacity for processing information. Psychological Review, 63, 81-97. www Neuhaus, H. (1973). The art of piano playing. New York: Praeger Publishers Inc. 
Noice, H., Chaffin, R., Jeffrey, J. \& Noice, T. (in press). Memorization by a jazz pianist: A case study. Music Psychology.

Noyle, L. J. (Ed.). (1987). Pianists on piano playing: Interviews with twelve concert pianists. Metuchen, NJ: Scarecrow.

Palmer, C., and Pfordresher, P. (2003). Incremental planning in sequence production. Psychological Review, 110, 683-712. [www

Palmer, C. (1997). Music performance. Annual Review of Psychology, 48, 115-138. [WWW

Palmer, C. (1989). Mapping musical thought to musical performance. Journal of Experimental Psychology: Human Perception and Performance, 15, 331-346. [WwW

Raaijmakers, J. G., \& Shiffrin, R. M. (1981). Search of associative memory. Psychological Review, 88, 93134.

Repp, B. H. (1992). Probing the cognitive representation of musical time: Structural constraints on the perception of timing perturbations. Cognition, 44, 241-281. WWw

Repp, B. H. (1995). Quantitative effects of global tempo on expressive timing in music performance: Some perceptual evidence. Music Perception, 13, 39-57.

Repp, B. H. (1998). Obligatory "expectations" of expressive timing induced by perception of musical structure. Psychological Research, 61, 33 - 43 [WwW

Roediger, H. L., III, and Crowder, R. C. (1976). A serial position effect in recall of United States presidents. Bulletin of the Psychonomic Society, 8 , 275-278.
Shaffer, L.H. (1984). Timing in solo and duet piano performances. Quarterly Journal of Experimental Psychology, 36A, 577-595.

Shaffer, L.H., Clarke, E.F., Todd, N.P. (1985). Meter and rhythm in piano playing. Cognition, 20, 61-77.

Stins, F. J., \& Michaels, C. F. (1999). Strategy differences in oscillatory tracking: Stimulus-hand versus stimulus manipulandum coupling. Journal of Experimental Psychology: Human Perception and Performance. 25, 1793-1812.

Sundberg, J., Friberg, A. \& Frydén, L. (1991). Threshold and preference quantities of rules for music performance. Music Perception, 9, 71-92.

Thompson, C. P.,. Cowan, T. M \& Frieman, J. (1993). Memory Search by a Memorist. Hillsdale, NJ: Lawrence Erlbaum Associates.

Todorov, E. \& Jordan, M.I. (2002). Optimal feedback control as a theory of motor coordination. Nature Neuroscience, 5, 1226-1235.

Tulving, E. (1962). Subjective organization in free recall of "unrelated" words. Psychological Review, 69, 344-354. Www

Van Orden, G.C., Holden, J.G. Turvey, M.T. (2003). Self-organization of cognitive performance. Journal of Experimental Psychology: General, 132, 331-350. Www Williamon, A., and Valentine, E. (2002). The role of retrieval structures in memorizing music. Cognitive Psychology, 44, 1-32. WWW

Williamon, A., Valentine, E. \& Valentine, J. (2002). Shifting the focus of attention between levels of musical structure. European Journal of Cognitive Psychology, 14, 493-520. 